\title{
Proteomic analysis of human spermatozoa proteins with oxidative stress
}

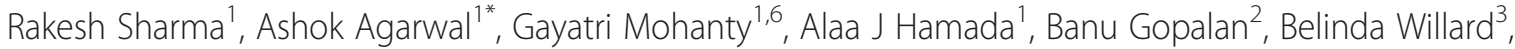 \\ Satya Yadav ${ }^{4}$ and Stefan du Plessis ${ }^{5}$
}

\begin{abstract}
Background: Oxidative stress plays a key role in the etiology of male infertility. Significant alterations in the sperm proteome are associated with poor semen quality. The aim of the present study was to examine if elevated levels of reactive oxygen species cause an alteration in the proteomic profile of spermatozoa.

Methods: This prospective study consisted of 52 subjects: 32 infertile men and 20 normal donors. Seminal ejaculates were classified as ROS+ or ROS- and evaluated for their proteomic profile. Samples were pooled and subjected to LC-MS/MS analysis through in-solution digestion of proteins for peptide characterization. The expression profile of proteins present in human spermatozoa was examined using proteomic and bioinformatic analysis to elucidate the regulatory pathways of oxidative stress.

Results: Of the 74 proteins identified, 10 proteins with a 2-fold difference were overexpressed and 5 were underexpressed in the ROS+ group; energy metabolism and regulation, carbohydrate metabolic processes such as gluconeogenesis and glycolysis, protein modifications and oxidative stress regulation were some of the metabolic processes affected in ROS+ group.

Conclusions: We have identified proteins involved in a variety of functions associated with response and management of oxidative stress. In the present study we focused on proteins that showed a high degree of differential expression and thus, have a greater impact on the fertilizing potential of the spermatozoa. While proteomic analyses identified the potential biomarkers, further studies through Western Blot are necessary to validate the biomarker status of the proteins in pathological conditions.
\end{abstract}

Keywords: Spermatozoa, Reactive oxygen species, Oxidative stress, Proteomics, Male infertility

\section{Background}

Male-factor infertility contributes to $50 \%$ of infertile couples worldwide, and while the causes are multifactorial, current research has focused on oxidative stress. Specifically, oxidative stress may lead to alterations in protein expression levels in spermatozoa, causing molecular and genetic defects. Research has already shown that oxidative stress is associated with a variety of male infertility diagnosis such as varicocele, idiopathic infertility, spinal cord injury, prostatitis and leukocytospermia [1-8]. Varicocele is implicated in $35 \%$ of men with primary infertility and in $80 \%$ of infertile men with secondary infertility, and oxidative stress

\footnotetext{
* Correspondence: Agarwaa@ccf.org

${ }^{1}$ Center for Reproductive Medicine, Glickman Urological and Kidney Institute, Cleveland Clinic, Cleveland, OH, USA

Full list of author information is available at the end of the article
}

is one of the many causes of varicocele related infertility [9-11]. Oxidative stress in men with varicocele is also associated both with motility and grade of varicocele.

Understanding the protein profile of spermatozoa is essential for identifying the protein alterations that occur as a result of increased production of ROS and for better diagnosis of male infertility. The development of 2dimensional-polyacrylamide gel electrophoresis (2-DE) coupled with Western blot have aided in the identification of proteins, in relation to sperm composition and function $[12,13]$. Furthermore advancements in mass spectrometry analyses of spermatozoa have broadened our knowledge and aided in the identification of pivotal sperm proteins $[14,15]$. Numerous studies have reported the presence of proteins in studies involving human spermatozoa through the implementation of proteomic techniques such as 2- 
DE, liquid chromatography tandem mass spectrometry (LC-MS/MS), matrix assisted laser desorption and ionization- time of flight tandem mass spectrometry (MALDI-TOF-MS/MS), and 2-dimensional difference in gel electrophoresis (DIGE) [16-21].

In this comparative study, we employed LC- MS/ MS and functional bioinformatic analyses to identify the relative abundance of proteins in spermatozoa obtained from seminal ejaculates of infertile men who were referred to the andrology clinical laboratory for advanced semen analysis (including parameters of oxidative stress such as levels of ROS in spermatozoa, concentration of antioxidant in the seminal plasma and the extent of DNA damage). We also included healthy men with high and low levels of ROS in their seminal ejaculates compared to those with low levels of ROS. Oxidative stress plays a major role in male infertility, but the crucial proteins that are differentially expressed in ROS are not known. Understanding the role of these proteins is therefore important in our understanding of the post-genomic events. It will help identify potential proteins that could serve as biomarkers to better manage and treat oxidative stress, and consequently, male infertility.

\section{Methods}

The study was approved by the Institutional Review Board of Cleveland Clinic and was conducted in accordance with national and international guidelines. A total of 52 subjects were enrolled in the study. Twenty healthy male volunteers of unproven fertility (normal semen analysis results but had not established a pregnancy) were selected on the basis of normal semen analysis. Thirty two infertile men attending our infertility clinic were referred to the andrology lab for advanced semen parameters of oxidative stress. The breakdown of the infertile subjects was as follows: primary infertility: $\mathrm{n}=25$ (25/32; 78.1\%); Secondary infertility: $\mathrm{n}=7$ (7/25; 28\%). Of the 25 men with primary infertility, $64 \%$ (16/25) had <2 years and 36\% (9/25) >2 years. Clinical varicocele (grade 1-2) was present in 10 (62.5\%) of the 16 men who presented with $<2$ years of primary infertility and in $5(55.6 \%)$ of the 9 men with $>2$ years of primary infertility. In the 7 patients with secondary infertility, 6 (85.7\%) had a clinical varicocele (grade 1-2).

Semen samples were collected by masturbation after 2-3 days of sexual abstinence and analyzed according to WHO 2010 criteria [22]. A complete semen analysis was performed on both donors and patients and included both macroscopic (volume, $\mathrm{pH}$, color, viscosity, liquefaction time, split or complete ejaculate) and microscopic parameters (concentration, motility, morphology, round cells and peroxidase or Endtz test). All subjects were also examined for levels of reactive oxygen species (ROS) in the seminal ejaculate. The remainder of the seminal ejaculate was frozen without any cryoprotectant and stored at $-55^{\circ} \mathrm{C}$ for proteomic analysis.

\section{Semen analysis}

After liquefaction, complete semen analysis was performed to evaluate the sperm parameters (sperm count, percentages motility and morphology), according to WHO guidelines [22]. Semen analysis was done using a MicroCell counting chamber (Vitrolife, San Diego, CA). Smears of the raw semen were stained with a Diff-Quik kit (Baxter Healthcare Corporation, Inc., McGaw Park, IL) for assessment of sperm morphology according to WHO criteria.

\section{Measurement of reactive oxygen species}

In the freshly ejaculated and completely liquefied semen, ROS levels were measured by a chemiluminescence assay using luminol (5-amino-2, 3- dihydro-1, 4-phthalazinedione). Test samples consisted of luminol $(10 \mu \mathrm{L}, 5 \mathrm{mM})$ and $400 \mu \mathrm{L}$ of semen. Negative controls were prepared by replacing the sperm suspension with phosphate buffered saline. Chemiluminescence was measured for 15 min using a Berthold luminometer (Autolumat Plus 953). Results were expressed as relative light units $(\mathrm{RLU}) / \mathrm{sec} / \times 10^{6}$ sperm. Reference value for ROS - group was: $<20$ $\mathrm{RLU} / \mathrm{s} / \times 10^{6}$ sperm. ROS levels $>20 \mathrm{RLU} / \mathrm{s} / \times 10^{6}$ sperm were considered positive [23].

\section{Separation of spermatozoa and In-solution Digestion of Proteins}

We were interested in examining the effect of ROS levels on the distribution / alteration of proteins in an effort to understand the underlying mechanism of infertility. Based on our published reference levels, all samples with ROS levels below $20 \mathrm{RLU} / \mathrm{sec} / \times 10^{6}$ sperm were considered to be ROS - and those with ROS levels $>20 \mathrm{RLU} / \mathrm{sec} / \times 10^{6}$ sperm were considered to be $\mathrm{ROS}+[23]$. For proteomic analysis, frozen seminal ejaculates from both the donors and patients were divided into 2 groups: ROS+ and ROS-, irrespective of the subject's clinical diagnoses. Samples were centrifuge at $10,000 \mathrm{~g}$ for 10 minutes to pellet the spermatozoa and the clear seminal plasma was discarded. Samples were pooled into ROS + and ROS - groups and solubilized in lysis buffer containing $2 \%$ octyl- $\beta$-glucopyranoside, $100 \mathrm{mM}$ dithiothreitol (DTT), 9.8 M urea and protease inhibitors [12]. Spermatozoa samples were stored overnight in the refrigerator to allow for complete lysis of the spermatozoa. The samples were first precipitated in cold acetone, solubilized in $6 \mathrm{M}$ urea, reduced with DTT, and alkylated with iodoacetamide. The samples were subsequently diluted to give a urea concentration $<2 \mathrm{M}$ and then digested with trypsin. The tryptic digestion was subjected to a C18 clean up and then brought up in $50 \mu \mathrm{L}$ of $1 \%$ acetic acid [12].

\section{Liquid chromatography- Mass Spectrometer analysis (LC-MS-MS)}

The LC-MS/MS system was a Finnigan LTQ linear ion trap mass spectrometer system (Thermo Finnigan). Ten $\mu \mathrm{L}$ 
volumes of the extract were injected on a self-packed high performance liquid chromatography column (Phenomenex Jupiter C18 reversed-phase capillary chromatography column). Peptides were eluted from the column by an acetonitrile $/ 0.1 \%$ formic acid gradient at a flow rate of $0.25 \mu \mathrm{L} / \mathrm{min}$. They were introduced into the source of the mass spectrometer on-line. The microelectrospray ion source was operated at $2.5 \mathrm{kV}$. The digest was analyzed using the data dependent multitask capability of the instrument acquiring full scan mass spectra to determine peptide molecular weights and product ion spectra to determine amino acid sequence in successive instrument scans [12].

\section{Data analysis}

The data were analyzed using all collision- induced dissociation spectra collected in the experiment to search the National Center for Biotechnology Information (NCBI) human reference sequence database with the search program MASCOT (Matrix Science, Boston, MA). Mascot is a mass spectral search algorithm that uses mass spectrometry data to identify proteins from primary sequence databases. These searches were used to identify the proteins present in the in-solution digestions. After identification, a database consisting of all proteins identified in these searches was created and used for a second set of searches performed with SEQUEST (Thermo Finnigan). SEQUEST is a tandem mass spectrometry data analysis program used for protein identification. Sequest identifies collections of tandem mass spectra to peptide sequences that have been generated from databases of protein sequences. The results from these SEQUEST searches were used to determine the spectral counts. These spectral count values were normalized by the total number of spectral counts for all proteins in the sample and the number of amino acids present in the protein. As the precision of the proteomic analysis has an average error of $10-20 \%$, a 2 -fold change in protein expression was considered significant.

Furthermore functional bioinformatics analysis were done using publicly available (Gene Ontology (GO) annotations from GO Term Finder [24] and GO Term Mapper [25], UNIPROT [26], STRAP [27] and BioGPS [28] and proprietary software packages (Ingenuity Pathway Analysis (IPA) from Ingenuity ${ }^{\circledR}$ Systems [29] and Metacore ${ }^{\text {min }}$ from GeneGo Inc. [30] to identify the differentially affected processes, pathways, interactions and cellular distribution of the proteins in the two study groups.

\section{Results}

Semen parameters and oxidative stress parameters

Most of the infertile men were diagnosed with primary infertility and varicocele. The median and $25^{\text {th }}$ and $75^{\text {th }}$ percentile for sperm concentration $\left(\times 10^{6} / \mathrm{mL}\right)$ in controls was 64.9 (45.4-74.9) versus patients 23.0 (13.0-41.4).
The median and $25^{\text {th }}$ and $75^{\text {th }}$ percentile motility in controls was 58.3(50.0-65.7) compared to infertile men 50.5 (36.8-58.0). Among the patients, 46.8\% (15/32) had $>1 \times 10^{6}$ round cells / mL compared to donors $35 \%(7 / 20)$ of the donors, of these 15 patients, $15.6 \%$ were positive for the Endtz test - a marker for granulocytes, which are the major contributors of ROS production. None of the donors was positive for the Endtz test. An overlap in morphology was seen in both the donors $(3.5 \% \pm 1.6 \%)$ and infertile men $(3.6 \% \pm 3.2 \%)$.

Among the patients 22 of $32(68.8 \%)$ were positive for ROS compared to 9 of 20 (45\%) in the controls. Levels of ROS were significantly lower (RLU/s/ $\times 10^{6}$ sperm) median and $25^{\text {th }}$ and $75^{\text {th }}$ percentile were seen in donors $[4.4(0,300.2)]$ compared to infertile men $[104(0,1341)]$. Among the primary infertility patients with $<2$ years of infertility, $80 \%$ were positive for ROS and $55.6 \%$ were positive in the patients with $>2$ years of primary infertility. A significantly larger percentage of men (83\%) were positive for ROS in those with secondary infertility. Teratozoospermia was present in $48 \%$ of men with primary infertility.

When all subjects were categorized into ROS+ and ROSgroups, ROS levels (RLU/s/10 sperm: median, $25^{\text {th }}, 75^{\text {th }}$ percentile) were significantly different and higher in the ROS+ group $[2236(33,4439)]$ group compared to the ROS - group [4 (0, 9); $\mathrm{P}<0.01)]$.

\section{MS identification of the differentially expressed proteins in ROS+ and ROS- samples}

In this study, we analyzed the differential expression of proteins in spermatozoa obtained from seminal ejaculates with high levels of ROS+ and those with normal levels (ROS-). Tables 1 and 2 show the primary proteins with their NCBI database index number, calculated molecular weight, isoelectric point (pI), peptide coverage and Mascot scores for ROS+ and ROS- groups. Based on the SEQUEST score, a total of 74 proteins were identified and differential expression was calculated based on the normalized spectral count ratios between ROS+ and ROS-. In the ROS+ group, proteins that had $>50 \%$ peptide coverage were: A-Kinase anchor protein 4 isoform 2; Lactotransferrin precursor; Tubulin, beta, 2; Tubulin, beta 4; Tubulin, alpha 3c; Ropporin, rhophilin associated protein 1B; Prolactininduced protein; Histone cluster 1, H2aa; Beta actin and Triosephosphate isomerase 1 isoform 1 . In the ROS-group, proteins that had $>50 \%$ peptide coverage were: A-Kinase anchor protein 4 isoform 2; Lactotransferrin precursor; Spermatogenic Tubulin, beta, 2 precursor; Tubulin, beta 4; Tubulin, alpha 3c; Ropporin, rhophilin associated protein 1B; Prolactin-induced protein; Histone cluster 1, H2aa and Triosephosphate isomerase 1 isoform 1 ;

Out of the total 74 proteins identified, 47 were overexpressed and 27 underexpressed in the ROS+ group; 15 proteins were significantly (2-fold) differentially 
Table 1 Protein name, NCBI database index number, calculated MW, pl, peptide coverage and Mascot score in ROS+ group

\begin{tabular}{|c|c|c|c|c|c|c|}
\hline \multirow[b]{2}{*}{ No. } & \multirow[b]{2}{*}{ Protein name } & \multirow{2}{*}{$\begin{array}{l}\text { NCBI database } \\
\text { index number }\end{array}$} & \multirow{2}{*}{$\begin{array}{l}\text { Calculated } \\
\text { MW (kDa) }\end{array}$} & \multirow[b]{2}{*}{ pl } & \multicolumn{2}{|c|}{ LTQ } \\
\hline & & & & & $\begin{array}{l}\text { Peptides } \\
\text { (Coverage) }\end{array}$ & $\begin{array}{c}\text { Mascot } \\
\text { score }\end{array}$ \\
\hline 1 & A-Kinase anchor protein 4 isoform 2 & 21493039 & 94 & 6.7 & $34(54 \%)$ & 10988 \\
\hline 2 & lactotransferrin precursor & 54607120 & 80 & 8.5 & $36(64 \%)$ & 7287 \\
\hline 3 & tubulin, beta, 2 & 5174735 & 50 & 4.7 & $24(68 \%)$ & 6702 \\
\hline 4 & tubulin, beta 4 & 21361322 & 50 & 4.8 & $19(57 \%)$ & 5071 \\
\hline 5 & glyceraldehyde-3-phosphate dehydrogenase, spermatogenic & 7657116 & 44 & 8.4 & $12(48 \%)$ & 5711 \\
\hline 6 & tubulin, alpha $3 c$ & 17921993 & 50 & 4.9 & $15(51 \%)$ & 2942 \\
\hline 7 & ropporin, rhophilin associated protein 1B & 59891409 & 24 & 5.1 & $7(56 \%)$ & 2587 \\
\hline 8 & semenogelin II precursor & 4506885 & 65 & 9.1 & $13(22 \%)$ & 2277 \\
\hline 9 & outer dense fiber of sperm tails 2 isoform 2 & 24430183 & 73 & 7.2 & $16(31 \%)$ & 2051 \\
\hline 10 & semenogelin I isoform a preproprotein & 4506883 & 52 & 9.3 & $12(31 \%)$ & 1983 \\
\hline 11 & $\begin{array}{l}\text { sperm protein associated with the nucleus, } \\
\mathrm{X} \text { chromosome, family member } \mathrm{C}\end{array}$ & 13435137 & 11 & 5.0 & $3(45 \%)$ & 1892 \\
\hline 12 & tubulin, alpha, ubiquitous & 57013276 & 50 & 4.9 & $13(46 \%)$ & 1616 \\
\hline 13 & glutathione S-transferase mu 3 & 23065552 & 26 & 5.3 & $7(37 \%)$ & 1595 \\
\hline 14 & prolactin-induced protein & 4505821 & 16 & 8.2 & $8(62 \%)$ & 1559 \\
\hline 15 & A Kinase anchor protein 3 & 21493041 & 95 & 5.8 & $20(35 \%)$ & 1416 \\
\hline 16 & histone cluster 1, H2ba & 24586679 & 14 & 10.3 & $1(11 \%)$ & 1371 \\
\hline 17 & mitochondrial malate dehydrogenase precursor & 21735621 & 35 & 8.9 & $8(33 \%)$ & 1342 \\
\hline 18 & histone cluster 1, H2aa & 25092737 & 14 & 10.8 & $6(58 \%)$ & 1334 \\
\hline 19 & clusterin isoform 1 & 42716297 & 58 & 6.2 & $6(16 \%)$ & 1204 \\
\hline 20 & ropporin & 21359920 & 24 & 5.5 & $6(43 \%)$ & 1184 \\
\hline 21 & sorbitol dehydrogenase & 156627571 & 38 & 8.2 & $7(35 \%)$ & 1095 \\
\hline 22 & mitochondrial ATP synthase beta subunit precursor & 32189394 & 56 & 5.2 & $16(53 \%)$ & 976 \\
\hline 23 & beta actin & 4501885 & 42 & 5.2 & $9(54 \%)$ & 909 \\
\hline 24 & triosephosphate isomerase 1 isoform 1 & 4507645 & 26 & 6.4 & $9(55 \%)$ & 761 \\
\hline 25 & glyceraldehyde-3-phosphate dehydrogenase & 7669492 & 36 & 8.5 & $6(32 \%)$ & 706 \\
\hline 26 & L-lactate dehydrogenase C- 1 peptide & 4504973 & 36 & 7.0 & $1(5 \%)$ & 674 \\
\hline 27 & fatty acid synthase & 41872631 & 275 & 6.0 & $3(8 \%)$ & 669 \\
\hline 28 & sperm autoantigenic protein 17 & 8394343 & 17 & 4.7 & $2(22 \%)$ & 592 \\
\hline 29 & pyruvate kinase, muscle isoform $\mathrm{M} 2$ & 33286418 & 58 & 7.9 & $11(38 \%)$ & 560 \\
\hline 30 & $\begin{array}{l}\text { ATP synthase, } \mathrm{H}+\text { transporting, mitochondrial F1 complex, } \\
\text { alpha subunit precursor }\end{array}$ & 4757810 & 59 & 9.1 & $8(23 \%)$ & 542 \\
\hline 31 & brain creatine kinase & 21536286 & 42 & 5.3 & $7(32 \%)$ & 511 \\
\hline 32 & heat shock protein $90 \mathrm{kDa}$ beta, member 1 & 4507677 & 92 & 4.7 & $6(10 \%)$ & 502 \\
\hline 33 & heat shock 70 kDa protein 2 & 13676857 & 70 & 5.5 & $10(21 \%)$ & 448 \\
\hline 34 & heat shock 90 kDa protein 1, alpha isoform 1 & 153792590 & 98 & 5.0 & $8(13 \%)$ & 447 \\
\hline 35 & saccharopine dehydrogenase (putative) & 55770836 & 47 & 9.2 & $5(29 \%)$ & 395 \\
\hline 36 & actin, alpha 1, skeletal muscle & 4501881 & 42 & 5.2 & $6(36 \%)$ & 374 \\
\hline 37 & glutamine synthetase & 19923206 & 42 & 6.4 & $3(9 \%)$ & 374 \\
\hline 38 & fructose-bisphosphate aldolase A & 4557305 & 39 & 8.3 & $5(29 \%)$ & 366 \\
\hline 39 & eukaryotic translation elongation factor 1 alpha 1 & 4503471 & 50 & 9.1 & $8(36 \%)$ & 347 \\
\hline 40 & fibronectin 1 isoform 3 preproprotein & 16933542 & 262 & 5.4 & $6(4 \%)$ & 321 \\
\hline 41 & prostate, ovary, testis expressed protein on chromosome 2 & 153791352 & 123 & 5.8 & $4(8 \%)$ & 317 \\
\hline
\end{tabular}


Table 1 Protein name, NCBI database index number, calculated MW, pl, peptide coverage and Mascot score in ROS+ group (Continued)

\begin{tabular}{|c|c|c|c|c|c|c|}
\hline 42 & acetyl-Coenzyme A acetyltransferase 1 precursor & 4557237 & 45 & 8.9 & $9(33 \%)$ & 316 \\
\hline 43 & voltage-dependent anion channel 2 & 42476281 & 32 & 7.4 & $4(22 \%)$ & 293 \\
\hline 44 & outer dense fiber of sperm tails 1 & 194248060 & 30 & 8.4 & $4(26 \%)$ & 283 \\
\hline 45 & phosphoglycerate kinase 2 & 31543397 & 45 & 8.7 & $5(30 \%)$ & 253 \\
\hline 46 & histone cluster 1, H2ae & 10645195 & 14 & 11.0 & $4(49 \%)$ & 251 \\
\hline 47 & protein disulfide - isomerase A3 precursor & 21361657 & 57 & 5.9 & $4(13 \%)$ & 243 \\
\hline 48 & acid phosphatase, prostate short isoform precursor & 6382064 & 44 & 5.8 & $5(16 \%)$ & 240 \\
\hline 49 & voltage-dependent anion channel 3 isoform b & 25188179 & 30 & 8.8 & $5(27 \%)$ & 226 \\
\hline 50 & phospholipase A2, group IIA precursor & 4505849 & 16 & 9.4 & $2(23 \%)$ & 202 \\
\hline 51 & transglutaminase 4 (prostate) & 156627577 & 77 & 6.3 & $8(17 \%)$ & 187 \\
\hline 52 & glutathione peroxidase 4 isoform A precursor & 75709200 & 22 & 8.6 & $4(32 \%)$ & 181 \\
\hline 53 & heat shock $70 \mathrm{kDa}$ protein 5 & 16507237 & 72 & 5.0 & $4(8 \%)$ & 161 \\
\hline 54 & heat shock protein beta-1 & 4504517 & 22 & 5.9 & $3(31 \%)$ & 160 \\
\hline 55 & angiotensin I converting enzyme 1 isoform 1 precursor & 4503273 & 150 & 5.9 & $3(4 \%)$ & 160 \\
\hline 56 & peroxiredoxin 6 & 4758638 & 25 & 6.0 & $2(16 \%)$ & 145 \\
\hline 57 & chaperonin containing TCP1, subunit 5 (epsilon) & 24307939 & 60 & 5.4 & $4(12 \%)$ & 142 \\
\hline 58 & valosin-containing protein & 6005942 & 89 & 5.1 & $3(7 \%)$ & 142 \\
\hline 59 & sperm acrosomal membrane protein 14 - 1 peptide & 19424138 & 13 & 5.4 & $1(11 \%)$ & 132 \\
\hline 60 & chaperonin containing TCP1, subunit 8 (theta) & 48762932 & 60 & 5.4 & $4(14 \%)$ & 131 \\
\hline 61 & L-lactate dehydrogenase $\mathrm{A}$ isoform 1 & 5031857 & 36 & 8.4 & $2(13 \%)$ & 124 \\
\hline 62 & phosphoglycerate dehydrogenase & 23308577 & 57 & 6.2 & $3(13 \%)$ & 112 \\
\hline 63 & clathrin heavy chain 1 & 4758012 & 193 & 5.4 & $4(5 \%)$ & 108 \\
\hline 64 & chaperonin containing TCP1, subunit 4 (delta) & 38455427 & 58 & 7.9 & $5(21 \%)$ & 99 \\
\hline 65 & peptidylprolyl isomerase $\mathrm{A}$ & 10863927 & 18 & 7.6 & $2(23 \%)$ & 96 \\
\hline 66 & fumarate hydratase precursor & 19743875 & 54 & 8.8 & $8(31 \%)$ & 92 \\
\hline 67 & RAB2A, member RAS oncogene family & 4506365 & 23 & 6.0 & $3(18 \%)$ & 92 \\
\hline 68 & olfactomedin 4 precursor & 32313593 & 57 & 5.5 & $2(5 \%)$ & 90 \\
\hline
\end{tabular}

expressed in the ROS+ samples compared to the ROS- samples.

Of the differentially expressed proteins, 15 proteins were overexpressed in the ROS+ samples while 5 were underexpressed in comparison to ROS- samples (Table 3). The overexpressed proteins included the histone cluster1; H2ba (HIST1H2BA); mitochondrial malate dehydrogenase precursor (MDH2); heat shock protein $90 \mathrm{kDa}$ beta, member 1 (HSP90B1); heat shock $70 \mathrm{kDa}$ protein 5 (HSPA5); glutamine synthetase (GLUL); transglutaminase 4 (prostate) (TGM4); glutathione peroxidase 4 isoform A precursor (GPX4); sperm acrosomal membrane protein 14 (SPACA4); olfactomedin 4 precursor (OLFM4) and chromosome 20 open reading frame 3 (C20orf3). Proteins that were found to be under expressed were: semenogelin II precursor (SEMG2); peroxiredoxin 6 (PRDX6); clathrin heavy chain 1 (CLTC); eukaryotic translation elongation factor 2 (EEF2) and enolase 1 (ENO1).
Gene ontology annotations of the proteins identified in ROS+ and ROS- samples

The cellular distributions of the 74 proteins present in the ROS+ and ROS- samples showed that there was a greater distribution of proteins in the intracellular region compared to the extracellular region (Figure 1A). A significant number of proteins were also distributed in the cytoplasmic region. The proteins involved in the biological processes showed a greater distribution in cellular processes $(21 \%)$ followed by metabolic processes (17\%) (Figure 1B).

Gene ontology annotation comparisons of the differentially expressed proteins in ROS+ and ROS- samples

Based on the Gene Ontology classifications, the majority of the differentially expressed proteins that were over or underexpressed in ROS+ group compared to the ROSgroup were localized to the cytoplasmic and intracellular 
Table 2 Protein name, NCBI database index number, calculated MW, pl, peptide coverage and Mascot score in ROS- group

\begin{tabular}{|c|c|c|c|c|c|c|}
\hline \multirow{2}{*}{ No. } & \multirow{2}{*}{ Protein name } & \multirow{2}{*}{$\begin{array}{l}\text { NCBI database } \\
\text { index number }\end{array}$} & \multirow{2}{*}{$\begin{array}{l}\text { Calculated } \\
\text { MW (kDa) }\end{array}$} & \multirow{2}{*}{ pl } & \multicolumn{2}{|l|}{ LTQ } \\
\hline & & & & & Peptides (Coverage) & Mascot score \\
\hline 1 & A-Kinase anchor protein 4 isoform 2 & 21493039 & 94 & 6.7 & $34(54 \%)$ & 11284 \\
\hline 2 & lactotransferrin precursor & 54607120 & 80 & 8.5 & $32(56 \%)$ & 6049 \\
\hline 3 & gyceraldehyde-3-phosphate dehydrogenase, & 7657116 & 44 & 8.4 & $12(48 \%)$ & 5959 \\
\hline 4 & spermatogenic tubulin, beta, 2 precursor & 5174735 & 50 & 4.7 & $25(68 \%)$ & 5842 \\
\hline 5 & semenogelin I isoform a preproprotein & 4506883 & 52 & 9.3 & $11(24 \%)$ & 4965 \\
\hline 6 & tubulin, beta 4 & 21361322 & 50 & 4.8 & $19(58 \%)$ & 4879 \\
\hline 7 & semenogelin II precursor & 4506885 & 65 & 9.1 & $15(25 \%)$ & 4205 \\
\hline 8 & tubulin, alpha $3 c$ & 17921993 & 50 & 4.9 & $15(56 \%)$ & 2645 \\
\hline 9 & ropporin, rhophilin associated protein 1B & 59891409 & 24 & 5.1 & $6(53 \%)$ & 2427 \\
\hline 10 & prolactin-induced protein & 4505821 & 16 & 8.2 & $8(62 \%)$ & 2164 \\
\hline 11 & A-kinase anchor protein 3 & 21493041 & 95 & 5.8 & $16(28 \%)$ & 1800 \\
\hline 12 & outer dense fiber of sperm tails 2 Isoform 2 & 24430183 & 73 & 7.2 & $16(31 \%)$ & 1722 \\
\hline 13 & $\begin{array}{l}\text { sperm protein associated with the Nucleus, } \\
\text { X chromosome, family Member C }\end{array}$ & 13435137 & 11 & 5.0 & $3(45 \%)$ & 1437 \\
\hline 14 & tubulin alpha 6 & 14389309 & 50 & 4.9 & $11(45 \%)$ & 1374 \\
\hline 15 & ropporin & 21359920 & 24 & 5.5 & $6(43 \%)$ & 1280 \\
\hline 16 & clusterin isoform 1 & 42716297 & 58 & 6.2 & $5(15 \%)$ & 1257 \\
\hline 17 & sorbitol dehydrogenase & 156627571 & 38 & 8.2 & $4(23 \%)$ & 1249 \\
\hline 18 & beta actin & 4501885 & 42 & 5.2 & $6(34 \%)$ & 1232 \\
\hline 19 & pyruvate kinase, muscle isoform M1 & 3328642 & 58 & 7.6 & $13(47 \%)$ & 1133 \\
\hline 20 & histone cluster 1, H2aa & 25092737 & 14 & 10.8 & $4(51 \%)$ & 1121 \\
\hline 21 & mitochondrial ATP synthase beta subunit precursor & 32189394 & 56 & 5.2 & $13(38 \%)$ & 1031 \\
\hline 22 & fatty acid synthase & 41872631 & 275 & 6.0 & $10(9 \%)$ & 935 \\
\hline 23 & glutathione S-transferase mu 3 & 23065552 & 26 & 5.3 & $7(32 \%)$ & 929 \\
\hline 24 & histone cluster 1, H2ba -1 peptide & 24586679 & 14 & 10.3 & $1(11 \%)$ & 823 \\
\hline 25 & fibronectin 1 isoform 3 preproprotein & 16933542 & 262 & 5.4 & $16(11 \%)$ & 790 \\
\hline 26 & L-lactate dehydrogenase $\mathrm{C}$ & 4504973 & 36 & 7.0 & $2(7 \%)$ & 693 \\
\hline 27 & heat shock $90 \mathrm{kDa}$ protein 1, alpha isoform 2 & 154146191 & 85 & 4.9 & $10(18 \%)$ & 682 \\
\hline 28 & glyceraldehyde-3-phosphate dehydrogenase & 7669492 & 36 & 8.5 & $3(15 \%)$ & 621 \\
\hline 29 & sperm autoantigenic protein 17 & 8394343 & 17 & 4.7 & $2(22 \%)$ & 552 \\
\hline 30 & triosephosphate isomerase 1 isoform 1 & 4507645 & 26 & 6.4 & $6(61 \%)$ & 530 \\
\hline 31 & mitochondrial malate dehydrogenase precursor & 21735621 & 35 & 8.9 & $5(23 \%)$ & 512 \\
\hline 32 & phosphoglycerate kinase 2 & 31543397 & 45 & 8.7 & $4(17 \%)$ & 506 \\
\hline 33 & heat shock $70 \mathrm{kDa}$ protein 2 & 13676857 & 70 & 5.5 & $8(22 \%)$ & 423 \\
\hline 34 & histone cluster 1, H2ae & 10645195 & 14 & 11.0 & $3(43 \%)$ & 392 \\
\hline 35 & acetyl-Coenzyme A acetyltransferase 1 precursor & 4557237 & 45 & 8.9 & $8(34 \%)$ & 388 \\
\hline 36 & eukaryotic translation elongation factor 1 alpha 1 & 4503471 & 50 & 9.1 & $7(30 \%)$ & 383 \\
\hline 37 & $\begin{array}{l}\text { ATP synthase, } \mathrm{H}+\text { transporting, mitochondrial F1 } \\
\text { complex, alpha subunit precursor }\end{array}$ & 4757810 & 59 & 9.1 & $8(22 \%)$ & 378 \\
\hline 38 & outer dense fiber of sperm tails 1 & 194248060 & 30 & 8.4 & $3(22 \%)$ & 334 \\
\hline 39 & voltage-dependent anion channel 2 & 42476281 & 32 & 7.4 & $3(19 \%)$ & 332 \\
\hline 40 & acid phosphatase, prostate short isoform precursor & 6382064 & 44 & 5.8 & $5(16 \%)$ & 326 \\
\hline 41 & brain creatine kinase & 21536286 & 42 & 5.3 & $7(29 \%)$ & 268 \\
\hline 42 & saccharopine dehydrogenase (putative) & 55770836 & 47 & 9.2 & $4(29 \%)$ & 265 \\
\hline
\end{tabular}


Table 2 Protein name, NCBI database index number, calculated MW, pl, peptide coverage and Mascot score in ROS- group (Continued)

\begin{tabular}{|c|c|c|c|c|c|c|}
\hline 43 & protein disulfide-isomerase A3 precursor & 21361657 & 57 & 5.9 & $2(9 \%)$ & 261 \\
\hline 44 & eukaryotic translation elongation factor 2 & 4503483 & 96 & 6.4 & $3(8 \%)$ & 261 \\
\hline 45 & heat shock protein $90 \mathrm{kDa}$ beta, member 1 & 4507677 & 92 & 4.7 & $5(8 \%)$ & 250 \\
\hline 46 & heat shock protein beta-1 & 4504517 & 22 & 5.9 & $4(36 \%)$ & 191 \\
\hline 47 & glutamine synthetase & 19923206 & 42 & 6.4 & $3(14 \%)$ & 179 \\
\hline 48 & valosin-containing protein & 6005942 & 89 & 5.1 & $7(18 \%)$ & 177 \\
\hline 49 & phospholipase A2, group IIA precursor & 4505849 & 16 & 9.4 & $2(23 \%)$ & 170 \\
\hline 50 & $\begin{array}{l}\text { tyrosine } 3 / \text { tryptophan } 5 \text {-monooxygenase activation } \\
\text { protein, zeta polypeptide }\end{array}$ & 4507953 & 27 & 4.7 & $2(19 \%)$ & 167 \\
\hline 51 & L-lactate dehydrogenase $\mathrm{A}$ isoform 1 & 5031857 & 36 & 8.4 & $2(7 \%)$ & 167 \\
\hline 52 & fructose-bisphosphate aldolase A & 4557305 & 39 & 8.3 & $3(16 \%)$ & 167 \\
\hline 53 & chaperonin containing TCP1, subunit 5 (epsilon) & 24307939 & 60 & 5.4 & $3(9 \%)$ & 157 \\
\hline 54 & voltage-dependent anion channel 3 isoform b & 25188179 & 30 & 8.8 & $4(26 \%)$ & 147 \\
\hline 55 & peroxiredoxin 6 & 4758638 & 25 & 6.0 & $4(33 \%)$ & 140 \\
\hline 56 & glutathione peroxidase 4 isoform $\mathrm{A}$ precursor & 75709200 & 22 & 8.6 & $5(43 \%)$ & 139 \\
\hline 57 & transglutaminase 4 (prostate) & 156627577 & 77 & 6.3 & $5(9 \%)$ & 136 \\
\hline 58 & enolase 1 & 4503571 & 47 & 7.0 & $3(12 \%)$ & 134 \\
\hline 59 & T-complex protein 1 isoform b & 57863259 & 44 & 7.5 & $5(30 \%)$ & 129 \\
\hline 60 & CSE1 chromosome segregation 1-like protein & 29029559 & 111 & 5.5 & $2(3 \%)$ & 128 \\
\hline 61 & fumarate hydratase precursor & 19743875 & 54 & 8.8 & $3(12 \%)$ & 115 \\
\hline 62 & lectin, mannose-binding 2 precursor & 5803023 & 40 & 6.4 & $2(13 \%)$ & 115 \\
\hline 63 & clathrin heavy chain 1 & 4758012 & 193 & 5.4 & $6(7 \%)$ & 111 \\
\hline 64 & chaperonin containing TCP1, subunit 4 (delta) & 38455427 & 58 & 7.9 & $4(19 \%)$ & 107 \\
\hline 65 & RAB2A, member RAS oncogene family & 4506365 & 23 & 6.0 & $3(18 \%)$ & 106 \\
\hline 66 & chromosome 20 open reading frame 3 & 24308201 & 46 & 5.8 & $3(19 \%)$ & 105 \\
\hline
\end{tabular}

regions (Figure 2). Specifically, the cellular compartments of intracellular, organelle, macromolecular complex region and mitochondria were predominantly occupied by the overexpressed proteins. The cytosolic, cytoplasm, extracellular, plasma membrane, protein complex and the vesicular region showed an abundance of underexpressed proteins when compared to the overexpressed ones. Strikingly, the endosome, lipid particle, membrane-bound organelles and the microtubules showed only the presence of overexpressed proteins in the ROS+ group while the proteinaceous extracellular matrix was restricted only to the underexpressed proteins.

GO analysis also revealed that the majority of over and under expressed proteins in the ROS+ group was found to be involved in cellular processes (Figure 3). The proteins involved in developmental processes, cellular process, interactions with cells and organisms, localization, metabolic processes and transport were common to both under and overexpressed proteins. Overexpressed proteins were abundantly expressed for these functions. Many of the processes such as cellular amino acid metabolic processes, cellular component biogenesis, chromosome organization, cytoskeleton organization, embryo development, gluconeogenesis and homeostatic processes were found to be restricted only to the overexpressed proteins. Similarly, the processes such as carbohydrate catabolic processes, cellular component movement, glycolysis, and response to unfolded protein were found to be restricted to the underexpressed proteins.

\section{Pathways and network analysis of differentially expressed} in ROS+ proteins using Ingenuity Pathway Analysis (IPA) and Metacore ${ }^{\text {TM }}$ software packages

A list of significantly enriched or topmost pathways and/or process networks associated with the over and underexpressed proteins in the ROS+ group is shown in Table 3. Cellular processes were comprised of cell cycle, cell adhesion, cellular morphology, cellular movement and cell death and cell survival. Protein modifications included protein folding and degradation; general metabolic pathways were: carbohydrate metabolism (such as glycolysis and gluconeogenesis), amino acid metabolism, energy metabolism and oxidative stress regulation. With respect to the pathways related to 
Table 3 Differentially expressed proteins in ROS- and ROS+ groups along with the spectral count and the spectral count ratio for the two groups

\begin{tabular}{|c|c|c|c|c|c|c|}
\hline Protein & NCBI \# & SC ROS- & NSC-ROS- & SC ROS+ & NSC-ROS+ & $\begin{array}{l}\text { NSC ratio in } \\
\text { ROS+/ROS- }\end{array}$ \\
\hline acetyl-Coenzyme A acetyltransferase 1 precursor (ACAT1) & 4557237 & 20 & 0.006 & 26.000 & 0.008 & 1.4 \\
\hline acid phosphatase, prostate short isoform precursor (ACPP) & 6382064 & 17 & 0.005 & 27.000 & 0.009 & 1.7 \\
\hline actin, alpha 1, skeletal muscle (ACTA1) & 4501881 & 0 & 0.000 & 8.000 & 0.003 & ROS + only \\
\hline A-kinase anchor protein 3 (AKAP3) & 21493041 & 76 & 0.022 & 70.000 & 0.022 & 1.0 \\
\hline A-kinase anchor protein 4 isoform 2 (AKAP4) & 21493039 & 497 & 0.145 & 467.000 & 0.147 & 1.0 \\
\hline angiotensin I converting enzyme 1 isoform 1 precursor (ACE) & 4503273 & 5 & 0.001 & 5.000 & 0.002 & 1.1 \\
\hline $\begin{array}{l}\text { ATP synthase, } \mathrm{H}+\text { transporting, mitochondrial F1 complex, } \\
\text { alpha subunit precursor (ATP5A1) }\end{array}$ & 4757810 & 28 & 0.008 & 30.000 & 0.009 & 1.2 \\
\hline beta actin (ACTB) & 4501885 & 53 & 0.015 & 36.000 & 0.011 & 0.7 \\
\hline brain creatine kinase (CKB) & 21536286 & 19 & 0.006 & 21.000 & 0.007 & 1.2 \\
\hline chaperonin containing TCP1, subunit 4 (delta) (CCT4) & 38455427 & 4 & 0.001 & 6.000 & 0.002 & 1.6 \\
\hline chaperonin containing TCP1, subunit 5 (epsilon) (CCT8) & 24307939 & 4 & 0.001 & 7.000 & 0.002 & 1.9 \\
\hline chaperonin containing TCP1, subunit 8 (theta) & 48762932 & 5 & 0.001 & 4.000 & 0.001 & 0.9 \\
\hline chromosome 20 open reading frame 3 (C20orf3) & 24308201 & 2 & 0.001 & 4.000 & 0.001 & 2.2 \\
\hline clathrin heavy chain 1 (CLTC) & 4758012 & 14 & 0.004 & 6.000 & 0.002 & 0.5 \\
\hline clusterin preproprotein (CLU) & 355594753 & 56 & 0.016 & 55.000 & 0.017 & 1.1 \\
\hline CSE1 chromosome segregation 1-like protein (CSE1L) & 29029559 & 3 & 0.001 & 0.000 & 0.000 & ROS- only \\
\hline enolase 1 (ENO1) & 4503571 & 7 & 0.002 & 2.000 & 0.001 & 0.3 \\
\hline eukaryotic translation elongation factor 1 alpha 1 (EEF1A1) & 4503471 & 28 & 0.008 & 33.000 & 0.010 & 1.3 \\
\hline eukaryotic translation elongation factor 2 (EEF2) & 4503483 & 12 & 0.003 & 5.000 & 0.002 & 0.5 \\
\hline fatty acid synthase (FASN) & 41872631 & 40 & 0.012 & 35.000 & 0.011 & 1.0 \\
\hline fibronectin 1 isoform 3 preproprotein (FN1) & 16933542 & 41 & 0.012 & 21.000 & 0.007 & 0.6 \\
\hline fructose-bisphosphate aldolase A (ALDOA) & 4557305 & 15 & 0.004 & 17.000 & 0.005 & 1.2 \\
\hline fumarate hydratase precursor (FH) & 19743875 & 5 & 0.001 & 7.000 & 0.002 & 1.5 \\
\hline glutamine synthetase (GLUL) & 19923206 & 4 & 0.001 & 12.000 & 0.004 & 3.2 \\
\hline glutathione peroxidase 4 isoform A precursor (GPX4) & 75709200 & 8 & 0.002 & 21.000 & 0.007 & 2.8 \\
\hline glutathione S-transferase mu 3 (GSTM3) & 23065552 & 50 & 0.015 & 65.000 & 0.020 & 1.4 \\
\hline glyceraldehyde-3-phosphate dehydrogenase (GAPDH) & 7669492 & 14 & 0.004 & 22.000 & 0.007 & 1.7 \\
\hline glyceraldehyde-3-phosphate dehydrogenase, spermatogenic (GAPDHS) & 7657116 & 210 & 0.061 & 185.000 & 0.058 & 1.0 \\
\hline heat shock 70 kDa protein 2 (HSPA2) & 13676857 & 26 & 0.008 & 22.000 & 0.007 & 0.9 \\
\hline heat shock 70 kDa protein 5 (HSPA5) & 16507237 & 5 & 0.001 & 11.000 & 0.003 & 2.4 \\
\hline heat shock $90 \mathrm{kDa}$ protein 1, alpha isoform 1 (HSP90AA1) & 153792590 & 39 & 0.011 & 26.000 & 0.008 & 0.7 \\
\hline heat shock protein 90 kDa beta, member 1 (HSP90B1) & 4507677 & 11 & 0.003 & 22.000 & 0.007 & 2.2 \\
\hline heat shock protein beta-1 (HSPB1) & 4504517 & 5 & 0.001 & 4.000 & 0.001 & 0.9 \\
\hline histone cluster 1, H2aa (HIST1H2AA) & 25092737 & 47 & 0.014 & 56.000 & 0.018 & 1.3 \\
\hline histone cluster 1, H2ae (HISTH1AE) & 10645195 & 14 & 0.004 & 13.000 & 0.004 & 1.0 \\
\hline histone cluster 1, H2ba (HIST1H2BA) & 24586679 & 22 & 0.006 & 49.000 & 0.015 & 2.4 \\
\hline lactotransferrin precursor (LTF) & 54607120 & 246 & 0.072 & 292.000 & 0.092 & 1.3 \\
\hline lectin, mannose-binding 2 precursor & 5803023 & 3 & 0.001 & 5.000 & 0.002 & 1.8 \\
\hline L-lactate dehydrogenase A isoform 1 (LDHA) & 5031857 & 10 & 0.003 & 9.000 & 0.003 & 1.0 \\
\hline L-lactate dehydrogenase C (LDHC) & 4504973 & 17 & 0.005 & 12.000 & 0.004 & 0.8 \\
\hline mitochondrial ATP synthase beta subunit precursor (ATP5B) & 32189394 & 50 & 0.015 & 70.000 & 0.022 & 1.5 \\
\hline mitochondrial malate dehydrogenase precursor (MDH2) & 21735621 & 22 & 0.006 & 44.000 & 0.014 & 2.2 \\
\hline
\end{tabular}


Table 3 Differentially expressed proteins in ROS- and ROS+ groups along with the spectral count and the spectral count ratio for the two groups (Continued)

\begin{tabular}{|c|c|c|c|c|c|c|}
\hline olfactomedin 4 precursor (OLFM4) & 32313593 & 1 & 0.000 & 4.000 & 0.001 & 4.3 \\
\hline outer dense fiber of sperm tails 1 (ODF1) & 194248060 & 15 & 0.004 & 14.000 & 0.004 & 1.0 \\
\hline outer dense fiber of sperm tails 2 isoform 2 (ODF2) & 24430183 & 90 & 0.026 & 91.000 & 0.029 & 1.1 \\
\hline peptidylprolyl isomerase A (PPIA) & 10863927 & 4 & 0.001 & 2.000 & 0.001 & 0.5 \\
\hline peroxiredoxin 6 (PRDX6) & 4758638 & 4 & 0.001 & 1.000 & 0.0003 & 0.3 \\
\hline phosphoglycerate dehydrogenase (PHGDH) & 23308577 & 3 & 0.001 & 5.000 & 0.002 & 1.8 \\
\hline phosphoglycerate kinase 2 (PGK2) & 31543397 & 17 & 0.005 & 9.000 & 0.003 & 0.6 \\
\hline phospholipase A2, group IIA precursor (PLA2G2A) & 4505849 & 6 & 0.002 & 10.000 & 0.003 & 1.8 \\
\hline prolactin-induced protein (PIP) & 4505821 & 118 & 0.034 & 101.000 & 0.032 & 0.9 \\
\hline prostate specific antigen isoform 1 preproprotein (KLK3) & 4502173 & 3 & 0.001 & 2.000 & 0.001 & 0.7 \\
\hline protein disulfide-isomerase A3 precursor (PDIA3) & 21361657 & 7 & 0.002 & 7.000 & 0.002 & 1.1 \\
\hline pyruvate kinase, muscle isoform M2 (PKM) & 33286418 & 49 & 0.014 & 31.000 & 0.010 & 0.7 \\
\hline RAB2A, member RAS oncogene family (RAB2A) & 4506365 & 3 & 0.001 & 3.000 & 0.001 & 1.1 \\
\hline ropporin (ROPN1) & 21359920 & 20 & 0.006 & 31.000 & 0.010 & 1.7 \\
\hline ropporin, rhophilin associated protein 1B (ROPN1B) & 59891409 & 73 & 0.021 & 73.000 & 0.023 & 1.1 \\
\hline saccharopine dehydrogenase (putative) (SCCPDH) & 55770836 & 13 & 0.004 & 16.000 & 0.005 & 1.3 \\
\hline semenogelin I isoform a preproprotein (SEMG1) & 4506883 & 171 & 0.050 & 101.000 & 0.032 & 0.6 \\
\hline semenogelin II precursor (SEMG2) & 4506885 & 513 & 0.149 & 226.000 & 0.071 & 0.5 \\
\hline sorbitol dehydrogenase (SORD) & 156627571 & 36 & 0.010 & 27.000 & 0.009 & 0.8 \\
\hline sperm acrosomal membrane protein 14 & 19424138 & 1 & 0.000 & 2.000 & 0.001 & 2.2 \\
\hline sperm autoantigenic protein 17 (SPA17) & 8394343 & 15 & 0.004 & 20.000 & 0.006 & 1.4 \\
\hline $\begin{array}{l}\text { sperm protein associated with the nucleus, } \\
X \text { chromosome, family member C (SPANX) }\end{array}$ & 13435137 & 54 & 0.016 & 80.000 & 0.025 & 1.6 \\
\hline transglutaminase 4 (prostate) (TGM4) & 156627577 & 4 & 0.001 & 9.000 & 0.003 & 2.4 \\
\hline triosephosphate isomerase 1 isoform 1 (TPI1) & 4507645 & 28 & 0.008 & 31.000 & 0.010 & 1.2 \\
\hline tubulin alpha 6 (TUBA1C) & 14389309 & 9 & 0.003 & 11.000 & 0.003 & 1.3 \\
\hline tubulin, alpha 3c (TUBA3C) & 17921993 & 117 & 0.034 & 134.000 & 0.042 & 1.2 \\
\hline tubulin, beta 4 (TUBB4A) & 21361322 & 36 & 0.010 & 30.000 & 0.009 & 0.9 \\
\hline tubulin, beta, 2 (TUBB4B) & 5174735 & 232 & 0.068 & 235.000 & 0.074 & 1.1 \\
\hline $\begin{array}{l}\text { tyrosine 3/tryptophan } 5 \text {-monooxygenase } \\
\text { activation protein, zeta polypeptide (YWHAZ) }\end{array}$ & 4507953 & 4 & 0.001 & 3.000 & 0.001 & 0.8 \\
\hline valosin-containing protein (VCP) & 6005942 & 16 & 0.005 & 9.000 & 0.003 & 0.6 \\
\hline voltage-dependent anion channel 2 (VDAC2) & 42476281 & 11 & 0.003 & 11.000 & 0.003 & 1.1 \\
\hline voltage-dependent anion channel 3 isoform b & 25188179 & 7 & 0.002 & 12.000 & 0.004 & 1.9 \\
\hline
\end{tabular}

A cut-off of 2-fold difference in NSC ratio was considered as significantly differentially expressed in ROS +. Overexpressed and underexpressed proteins are shown in bold.

carbohydrate metabolism, enzymes operating in gluconeogenesis and glycolysis including phosphoglycerate kinase 2 (PGK2) and glyceraldehyde phosphate dehydrogenase-S (GAPD-S) were found to be underexpressed in the ROS + group for both gluconeogenesis and glycolysis while glyceraldehyde-3-phosphate dehydrogenase (GAPDH), fructose-biphosphate aldolase A(ALDOA) and mitochondrial malate dehydrogenase precursor $(\mathrm{MDH} 2)$ were overexpressed. The overexpressed proteins, especially in the glycolytic pathway, were triosephosphate isomerase 1 (isoform 1(TPI1), glyceraldehyde-3 phosphate dehydrogenase (GAPDH) and fructose-biphosphate aldolase A (ALDOA). Two enzymes involved in the fermentation of pyruvate to lactate - L-lactate dehydrogenase C (LDHC) and L-lactate dehydrogenase A isoform 1(LDHA) were underexpressed. In addition, two enzymes functional in sucrose degradation pathways - triosephosphate isomerase 1 (TPI1) and fructose biphosphate aldolase A (ALDO A), were overexpressed.

Transcriptional regulatory network analysis of the differentially expressed proteins, using Metacore $^{\mathrm{TM}}$, showed that the androgen receptor was one of the topmost regulators 


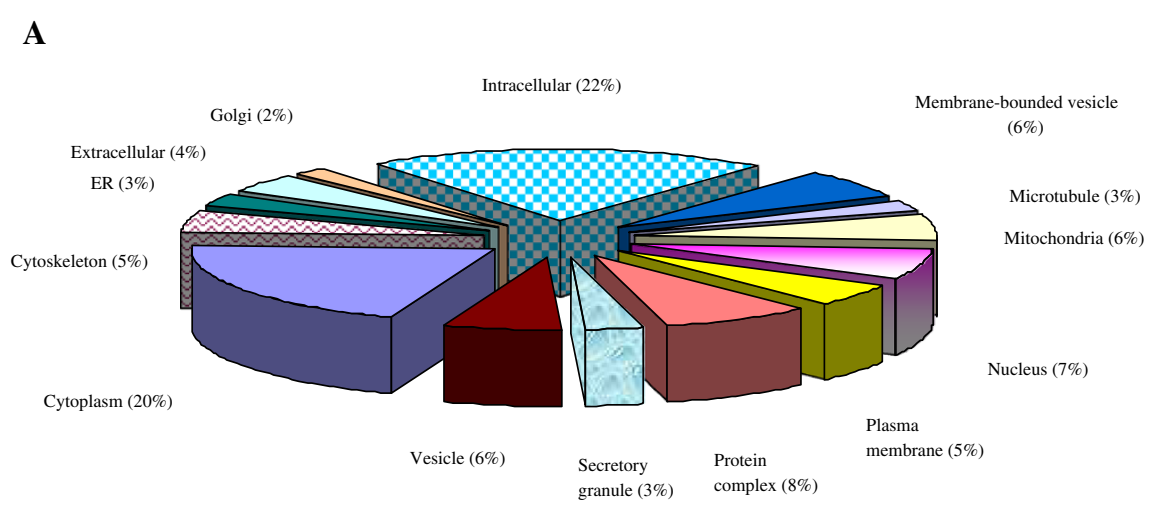

B

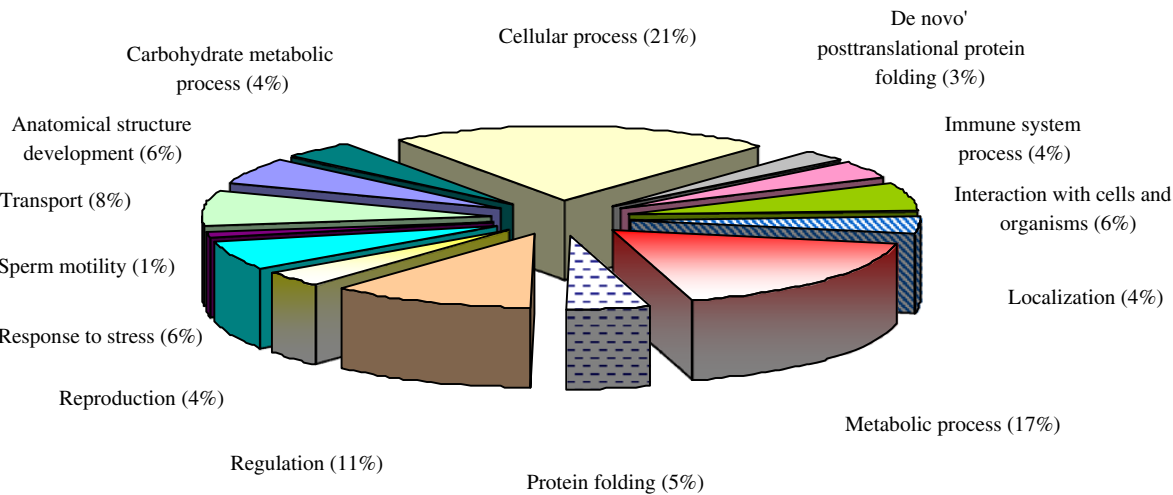

Figure 1 Functional annotations from consolidated publicly available software tools A: Cellular distribution showing the maximum distribution was intracellular (22\%) followed by cytoplasmic distribution; B: Biological processes distribution of proteins identified in spermatozoa from ROS+ and ROS- group showing the highest distribution was in the cellular processes (21\%) followed by metabolic processes.

with 21 differentially expressed proteins in the ROS+ group interacting with the receptor (Figure 4). As a result of the established connection between germ cell development and the levels of androgens, it was important to elucidate the potential interaction of these over- and underexpressed proteins with the androgen receptor. One of the pathways that may be relevant to spermatogenesis is cAMP responsive element modulator (CREM) signaling in the testis (Figure 5). In this pathway, 3 proteins were found to be differentially expressed. Angiotensin I converting isoform 1 precursor (ACE). The outer dense fiber of sperm tails 1 (ODF1) was found to be underexpressed whereas the $\mathrm{L}$ - lactate dehydrogenase $\mathrm{C}$ (LDHC) was overexpressed in ROS+ sample compared with ROS- sample.

\section{Discussion}

Oxidative stress plays a key role in the etiology of male infertility, possibly by altering protein expression levels in spermatozoa, causing molecular and genetic defects. Therefore, understanding the function of each protein involved and the post-translational modifications that occur during spermmaturation is important and may lead to a useful biomarker for male infertility. In earlier studies, we demonstrated that ROS are independent of the semen parameters [6]. Therefore, in the current study, we compared the sperm proteome from a group of men with high levels of ROS (ROS+) with that from men with low or physiological levels of ROS (ROS-). The ROS grouping was done irrespective of the patient's clinical diagnoses and semen parameters: the only criteria was the presence or absence of ROS.

We have identified 74 proteins, 15 of which had a $>2$-fold difference in their expression levels in the ROS+ group when compared to the ROS-group. Based on the spectral counts of the 74 proteins, we identified 47 were overexpressed and 27 that were underexpressed in the ROS+ group compared to the ROS- group. Of the 74 proteins, 17 were determined to be either in their precursor or pre-protein form. The presence of these incompletely processed proteins is indicative of posttranslational processing problems as reported by some investigators [31,32]. Accumulation of precursor forms of protein may result in deregulation of the downstream functions of the mature protein [31]. Oxidative stress may result in the accumulation of precursors or preproteins. 


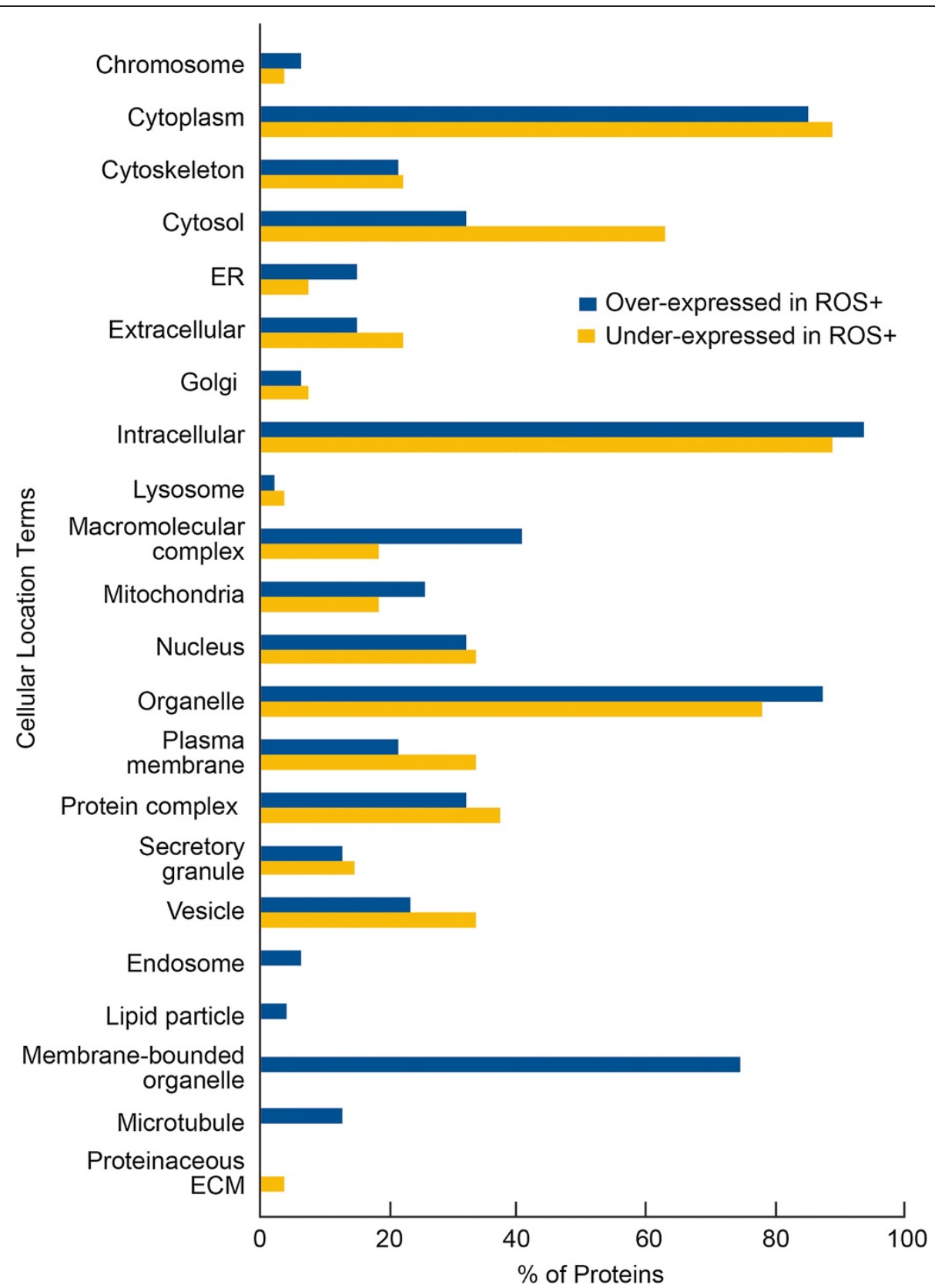

Figure 2 Cellular distribution showing the proteins that were significantly overexpressed in ROS + group were located in the cytoplasm, intracellular, organelle and membrane-bound organelle and underexpressed in ROS + group were located in the cytoplasm, cytosol, intracellular and organellar.

The cellular distribution of all the proteins as ascertained by GO analysis (Figure $1 \mathrm{~A}$ ) suggested that the majority of the proteins (68 proteins) were intracellular or organellar (62 proteins) in origin, whereas a few were localized in the extracellular (13 proteins) region. The presence of extracellular proteins may be attributed to the presence of round cells in the ejaculate from both the donors and patients. We did not remove these from subsequent processing for proteomic analysis.
Similar comparative studies have been performed previously by other groups in an effort to understand the sperm proteome $[31,33,34]$. Most notable amongst these are two studies where the expression profile of proteins was compared in asthenozoospermic and normozoospermic donors $[31,33]$. In these studies, 10 proteins and 17 spots were identified using 2-DE suggesting their role in motility-related male infertility. Xu et al conducted a comparative study between infertile patients and normozoospermic group and 


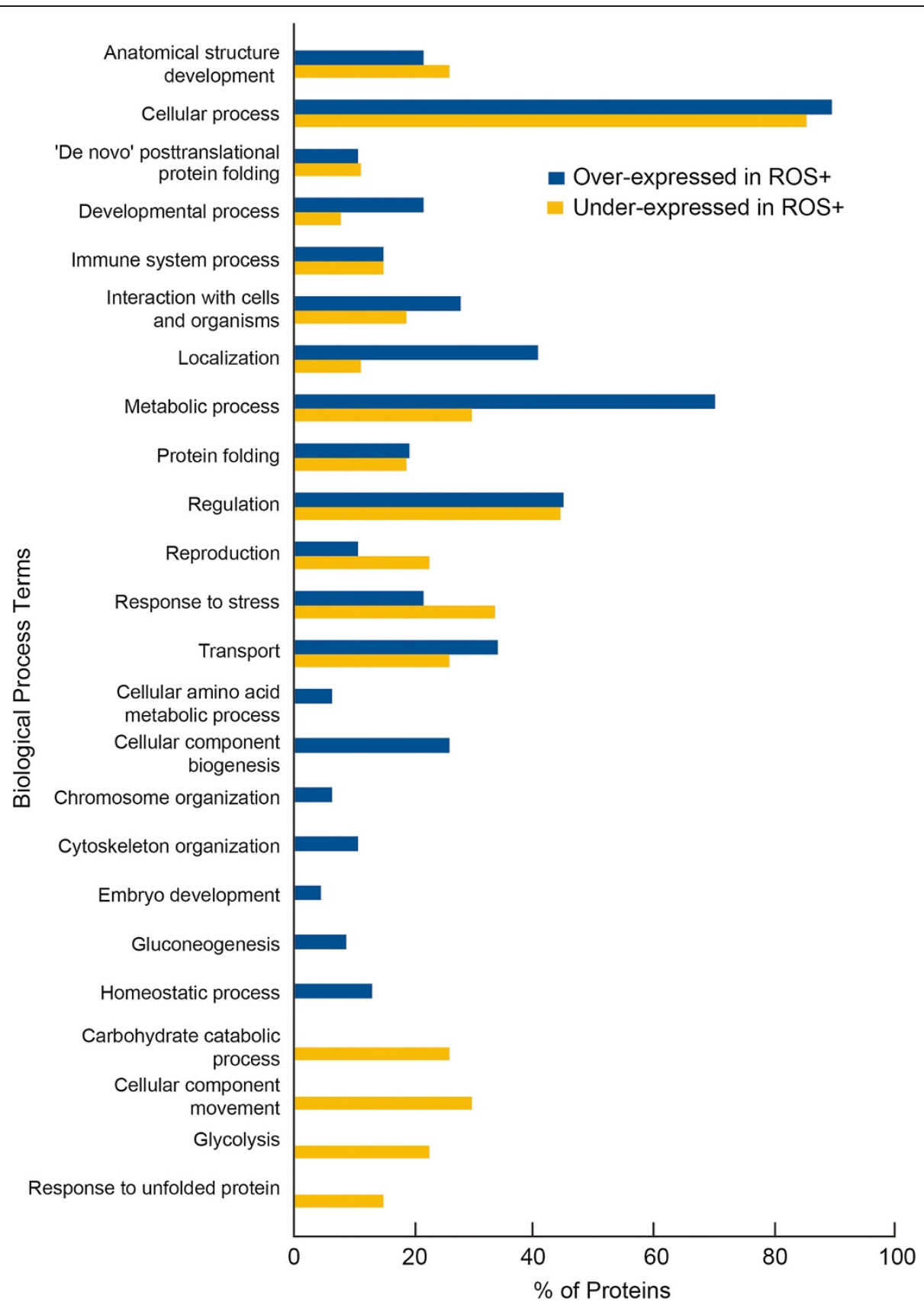

Figure 3 Biological process distribution of proteins of overexpressed were cellular processes, metabolic processes, localization, regulation and transport in spermatozoa from ROS + compared to cellular preocesses, regulation, response to stress, cellular movement and glycolysis in ROS- group.

identified 24 differentially expressed proteins that could potentially serve as diagnostic markers in identifying the underlying pathology of male infertility [35]. Our findings in this study are novel, as we have compared and identified the proteins that are differentially expressed in spermatozoa obtained from seminal ejaculates with high levels of ROS (ROS+) to those normal levels of ROS (ROS-).
On examining the association of the differentially expressed proteins with the biological processes (Figure 1B), we concluded that the majority of the proteins were involved in cellular, metabolic, and regulatory processes. A smaller distribution of proteins (3-5\%) was also found in biological processes such as de novo post translational (8 proteins) and protein folding (14 proteins), 


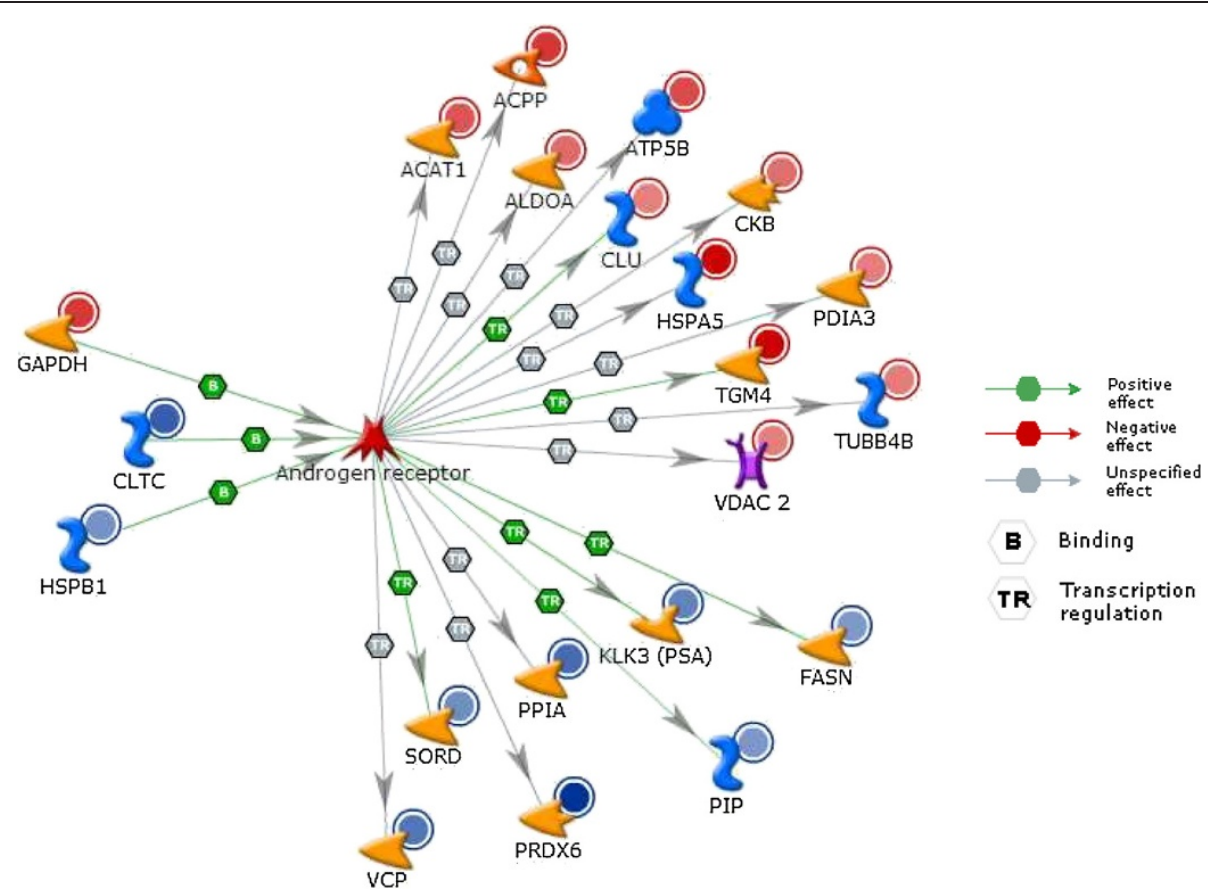

Figure 4 Transcriptional regulatory network showing interactions between differentially expressed ROS + proteins and androgen receptor. Proteins with red or blue circles around them are over-expressed (HSPA5 and TGM4) or underexpressed (PRDX6) in spermatozoa from the ROS + (relative to ROS-) group. The levels of expression values are reflected in the intensity of red or blue colors. Green arrows with a hexagon indicate positive effect. TR = Transcription regulation; PGK2 = phosphoglycerate kinase 2; GAPD-S = glyceraldehyde phosphate dehydrogenase-S; GAPDH = glyceraldehyde-3-phosphate dehydrogenase; ALDOA = fructose-biphosphate aldolase A; and $\mathrm{MDH} 2$ = mitochondrial malate dehydrogenase precursor.

and these were identified as 'enriched processes' for our list of proteins, by the GO Term Finder.

Even though the spermatozoa become transcriptionally inactive after spermatogenesis, we found the presence of the translational proteins and this may be indicative of the presence of some leftovers from inefficient spermatogenesis. They may also have a role in the normal physiology of the spermatozoa or affect fertilization and embryo development. Further validation through the pathway and process network analysis using IPA and Metacore $^{\mathrm{tm}}$, suggested that the topmost function of the differentially expressed proteins was carbohydrate metabolism and included pathways of gluconeogenesis, glycolysis, fermentation of pyruvate to lactate and sucrose degradation. There is a great controversy pertaining to the major pathway of energy metabolism during sperm motility [36-39]. In this context, our findings showed that while oxidative phosphorylation is important for sperm function, the major pathway for energy production for sperm motility was via the glycolytic pathway. To support this view, various respiratory enzymes involved in the glycolytic pathway including phosphoglycerate kinase 2 (PGK2), glyceraldehyde-3phosphate dehydrogenase (GAPDH), fructose- biphosphate aldolase A (ALDOA), glyceraldehyde-3 phosphate dehydrogenase-S (GAPDHS), triosephosphate isomerase 1 isoform (TPI1) were identified in our study. Furthermore, GAPDH-S protein was overexpressed in the ROS+ sample. Oxidation of GAPDH-S as a result of $\mathrm{H}_{2} \mathrm{O}_{2}$ generation has been reported to decrease sperm motility and inhibit GAPDH-S activity [40].

Various isoforms of histone proteins were also identified and these included histone cluster 1, H2aa (HIST1H2AA), histone cluster1 H2ae (HISTH1AE) and histone cluster1 and H2ba (HIST1H2BA). Histones are a group of proteins that are replaced by the protamines during sperm maturation in the epididymal region [41]. Their presence in the ejaculated spermatozoa is indicative of improper packaging of sperm chromatin and subsequent DNA damage. These findings have been attributed to oxidative stress [5,41].

We found 17 precursor proteins to be dysregulated; of these, 10 were over-expressed and 5 were underexpressed with a 2-fold difference between the ROS+ and ROSgroups. The differentially expressed proteins were mainly intracellular, cytoplasmic or organellar in distribution. This is contrary to the findings of $\mathrm{Xu}$ et al, who reported a higher distribution of differentially expressed proteins in the extracellular region in the infertile groups with normal semen parameters [35]. This difference may be attributed to the import/export of epididymal and seminal vesicle proteins. Furthermore, the distribution of overexpressed and underexpressed proteins in the ROS+ group revealed 


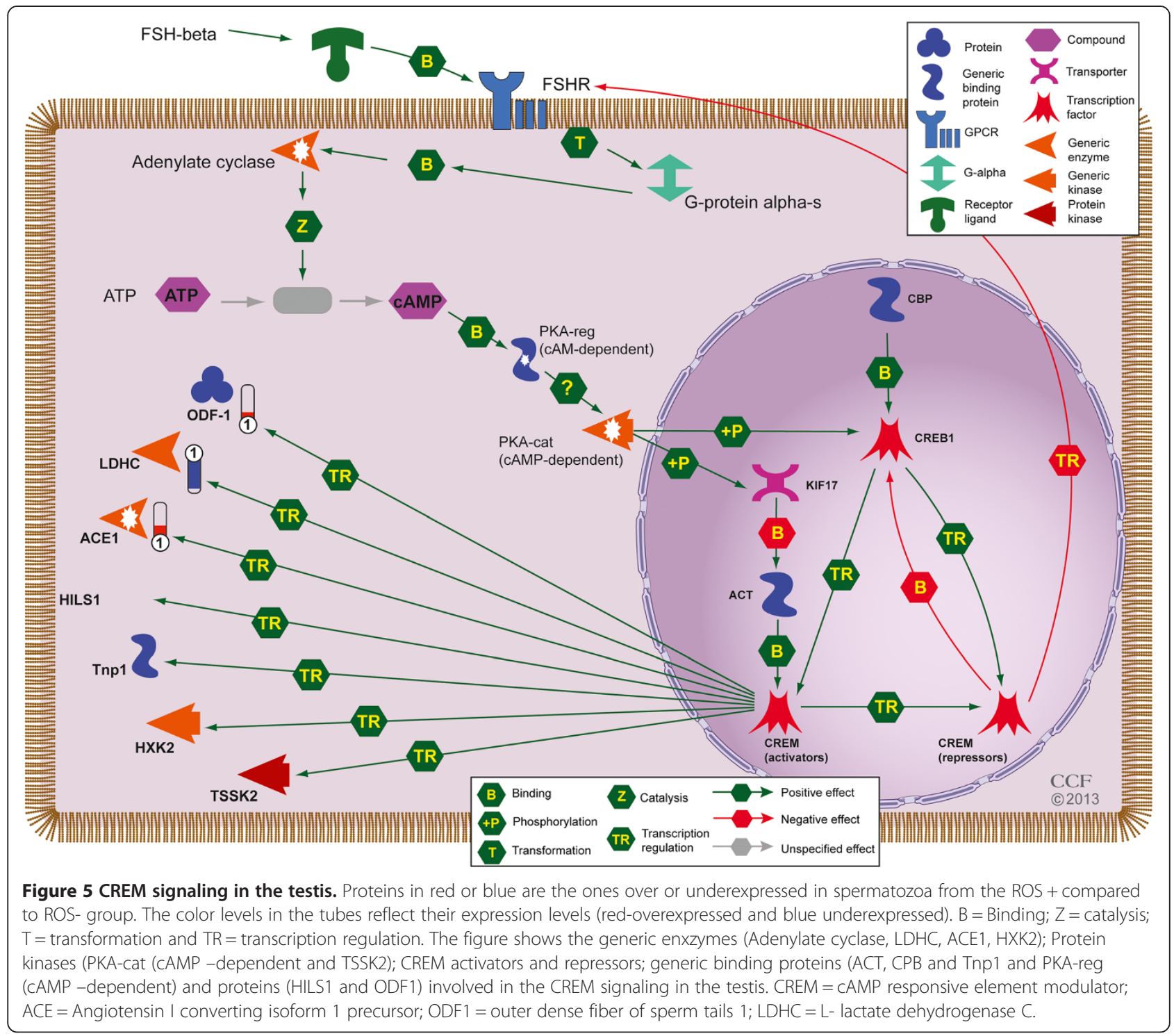

their involvement in various processes. We noted that many proteins showing significant changes in expression between the ROS+ and ROS- groups had roles in sexual reproduction, metabolic processes and stress response (Figures 2 and 3).

Our data suggests that semenogelin II precursor (SEMG2), which is involved in sexual reproduction, was underexpressed in the ROS+ group. Overexpression of semenogelin I and II precursor has been reported in previous comparative studies [31,35]. Xu et al reported an increase in both isoforms of semenogelin in the spermatozoa of infertile patients compared to the normozoospermic men [35]. Semenogelin -1 and semenogelin -2 have been reported in men with varicocele only as well as in men with varicocele with a history of moderate as well as heavy smoking. Semenogelin is known to cause a decrease in sperm motility, but it was within the normal range in the
ROS+ samples. Semenogelin (SEMG) is the major protein of seminal fluid proteins (20-40\%) and is secreted from seminal vesicles, epididymis, and prostate $[42,43]$. It is an androgen dependent protein that exists in two forms I $(52 \mathrm{kDa})$ and II (71-76 kDa). SEMG helps in the formation of the semen coagulum that is degraded later by prostatespecific antigen. SEMG counteracts oxidative stress by reducing the generation of free radicals through several mechanisms: slow sperm motility of the entrapped sperm, reduced energy consumption, free radical generation and inhibition of superoxide radical generation through direct interference with sperm NADH oxidase [44].

A great number of proteins are involved in the energy production required for the spermatozoon tail movement. We identified several proteins that are involved in energy producing processes such as the carbohydrate metabolic pathways of glycolysis and gluconeogenesis. Enolase I 
(ENO1) was found to be significantly underexpressed while respiratory enzyme mitochondrial malate dehydrogenase precursor (MDH2) was found to be overexpressed. $\mathrm{MDH} 2$ is an ROS producing enzyme localized in the sperm mitochondria [45]. It catalyzes the last step of the Krebs cycle when malate is converted into oxaloacetate using NAD+/NADH as intermediates. Several of the chaperone proteins such as heat shock protein $90 \mathrm{kDa}$ beta, member 1 (HSP90B1) and heat shock $70 \mathrm{kDa}$ protein 5 (HSPA5) were also seen to be overexpressed in response to stress. The association of these proteins with various processes related to cellular stressors such as heat, glucose deprivation, free radical attack, and infection indicates that ROS induces a stress response in the spermatozoa [46-48].

The GO annotations further revealed the involvement of overexpressed proteins in cellular amino acid metabolic processes. Examples of proteins that were found to be overexpressed included transglutaminases (TGM4) and glutamine synthetases. Transglutaminases are a family of calcium-dependent enzymes that catalyze the posttranslational modification of the selected glutamine residues on proteins by cross-linking with the peptidebound lysine residues or incorporating polyamines $[49,50]$. Transglutaminase that is secreted from the prostate is known as TGM4 prostate. A recent study showed increased levels of transglutaminase in response to oxidative stress in the prostate [51]. Excessive production of ROS has been reported to induce cell senescence, oxidative protein modifications, and cell membrane damage, increase intracellular calcium and activate certain cytokines such as TGFb [51]. Oxidative stress impacts the aggregation, increased molecular weight, unfolding, denaturation and proteolysis of cellular proteins. These effects may result in the initiation of cellular hyperamonemia, which probably triggers the expression of glutamate synthetase to redirect the production of the released ammonium into glutamate [52].

Glutathione peroxidase 4 isoform A precursor (GPX4) and peroxiredoxin 6 (PRDX6) function to reduce oxidative stress. The former was overexpressed and the latter was underexpressed in the ROS+ group. GPX4 is a well-known antioxidant enzyme and its increased expression in sperm in the ROS+ samples is reflective of its influence on genes synthesizing this enzyme. PRDX6 also belongs to a family of antioxidant enzyme known as peroxiredoxins. They detoxify $\mathrm{H}_{2} \mathrm{O}_{2}$ similar to catalase or glutathione peroxidases (GPXs) [53,54]. Peroxiredoxin 6 is localized in the sperm head (postacrosomal region and equatorial segment) and sperm tail [55]. Reduced levels of peroxiredoxins (PRDX1 and PRDX6) have been reported in infertile men with oxidative stress. Reduced levels of PRDX6 have also been reported in the seminal plasma from men with varicocele. Differential amounts of peroxiredoxin 6 have been reported (41\% in men with varicocele and $65 \%$ in men with idiopathic infertility) [56]. Human spermatozoa are reported to have high sensitivity to ROS and may be a result of reduced recycling of peroxiredoxins after exposure to oxidative stress [55].

Optimal levels of expression and function of androgens are central to the process of spermatogenesis. To understand the dependency of the differentially expressed proteins in the ROS+ groups, a network was derived to identify proteins regulated by androgen receptors. Spermatogenesis is dependent on androgen action and androgens act by stimulating the receptors present on the Sertoli cells $[57,58]$. Transcriptional network analysis (Figure 4) showed that 21 proteins were regulated by the androgen receptor. In our study, several proteins appeared to be transcriptionally activated by the androgen receptor but the effect of the androgen receptor on several other proteins is still unknown (Figure 5). Stanton et al reported that any loss to the androgen stimulus during meiosis induces changes in the proteins that are associated with various molecular processes such as apoptosis, cell signaling, oxidative stress and RNA processing [58]. These investigators further validated this observation by immunostaining for oxidized DNA adducts - they showed that spermatocytes that undergo oxidative stress induced DNA damage during androgen suppression. The completion of meiosis requires androgen action via the Sertoli cell [59]. Low levels of testicular androgens support meiosis while a high level is required for spermiogenesis.

Testicular testosterone suppression has been shown to adversely influence antioxidant activity [60]. The present study utilizing Network analysis revealed heat shock protein beta-1 (HSPB1) and clathrin heavy chain 1 (CLTC), which are known to bind and activate androgen receptor were actually underexpressed in the ROS+ group. We also observed that GAPDH levels were overexpressed, and that it was bound with the androgen receptor to impart a stimulatory effect in the ROS+ sample. The mechanism by which the androgen stimulus is transduced by the Sertoli cell to the germ cells is still unclear. In addition, it is well known that in majority of the infertility cases attributed to a male factor, spermatogenic arrest is a common feature. The process of spermatogenesis is dependent on the cAMP responsive element modulator (CREM) signaling pathway in the testis which operates in coordination with the CREM modulators (repressors and activators) [61]. CREM is essential for male fertility and the absence of CREMdependent transcription in post-meiotic germ cells is known to result in an arrest of spermatid differentiation and apoptosis $[62,63]$. CREM repressors are expressed during pre-meiotic germ cells while CREM activators are expressed in the post-meiotic germ cells. In order to understand the impact of oxidative stress on impaired spermatogenesis, we examined the CREM signaling in testis. Our findings revealed that three of the identified 
proteins that were differentially expressed in the ROS+ group were modulated by CREM activators. This included ODF1 and ACE1 proteins that were underexpressed as well LDHC, which was overexpressed. These findings suggest that oxidative stress may affect the switching of genes at the spermatogenic level. Comparative studies on CREM signaling in testis have been conducted on normo- and oligozoospermic men and men with round spermatids vs. round spermatid maturation arrest [64]. These findings further support the fact that a lack of a switch in the expression of CREM gene isoforms may have an adverse impact on spermatogenesis in humans.

To summarize, in this study, we have identified various proteins that are implicated in a multitude of functions associated with response and management of oxidative stress. The increased expression of histone cluster 1H2ba (HIST1H2BA), mitochondrial malate dehydrogenase precursor $(\mathrm{MDH} 2)$, transglutaminase 4 (TGM4), glutathione peroxidase 4 isoform A precursor (GPX4), glutamine synthetase (GLUL), heat shock proteins (HSP90B1 and HSPA5) in the ROS+ sample suggests that these proteins can serve as potential biomarkers of oxidative stress. Thus alterations reported in our study in men with and without oxidative stress may help explain pathways leading to the altered semen phenotype especially in men exhibiting oxidative stress both in infertile men as well as in infertile men with varicocele. However, the interaction between the proteins and the androgen receptors is still unclear and warrants further investigation. It is important to accurately assess the protein levels and verify that the differentially expressed proteins are indeed involved in the process of oxidative stress and are possibly modified as a result of oxidative stress. In future studies, as a follow-up to the present study, quantitative estimation of the differentially (overexpressed and underexpressed) expressed proteins, utilizing western blotting and antibodies is warranted. The findings of our study provide the groundwork for further testing including the proposition that these newly identified sperm proteins play crucial roles in oxidative stress and the pathophysiology of male infertility.

\section{Competing interests}

The authors declare that they have no competing interests.

\section{Authors' contributions \\ RK: participated in the study conception/design, review of the data and writing of the manuscript and final approval; SD: acquisition and preparation of samples for analysis; BW, acquisition of samples for analysis; interpretation of the results; SY: acquisition of the samples, interpretation of the data, discussion o results; BG: contributed to bioinformatic analysis, data interpretation and participated in the paper redaction; $\mathrm{AH}$ : drafting of the article; GM participated in the review of the data and writing of the manuscript; AA contributed to the study design, and review of the data. All authors read and approved the final manuscript.}

\section{Acknowledgements}

This study was supported by Cleveland Clinic, Research Program Committee. Authors wish to thank the Cleveland Clinic Andrology laboratory personnel for their help with scheduling of subjects used in this study.
This research project was supported in part by funds from the Cleveland Clinic Research Program Committee and the Center for Reproductive Medicine. Visit of GM supported in part by the INSPIRE fellowship from the Department of Science and Technology, New Delhi, India.

\section{Author details}

${ }^{1}$ Center for Reproductive Medicine, Glickman Urological and Kidney Institute, Cleveland Clinic, Cleveland, OH, USA. ${ }^{2}$ Bioinformatics Core Services, Lerner Research Institute, Cleveland Clinic, Cleveland, OH, USA. ${ }^{3}$ Proteomic Core Lab, Lerner Research Institute, Cleveland Clinic, Cleveland, OH, USA. ${ }^{4}$ Molecular Biotechnology Core lab, Lerner Research Institute, Cleveland Clinic, Cleveland, $\mathrm{OH}$, USA. ${ }^{5}$ Medical Physiology, Stellenbosch University, Tygerberg, South Africa. ${ }^{6}$ Permanent address: Ravenshaw University, Cuttack, Odisha, India.

Received: 4 March 2013 Accepted: 16 May 2013

Published: 20 May 2013

\section{References}

1. Sharma R, Aaron T, Kothari S, Agarwal A: A comprehensive overview Oxidative stress in male reproduction. In Free Radical Biomedicine. Edited by Pantopoulos K, Schipper H. Hauppauge NY: Nova Science Publishers Inc; 2012:305-328. Chapter 13.

2. Agarwal A, Cocuzza M, Abdelrazik H, Sharma RK: Oxidative stress measurement in patients with male or female factor infertility. In Handbook of Chemiluminescenct Methods in Oxidative Stress Assessment. Edited by Popov I, Lewin G. Kerala, India: Transworld Research Network; 2009:195-218.

3. Mahfouz R, Sharma R, Thiyagarajan A, Kale V, Gupta S, Sabanegh E, Agarwal $A$ : Semen characteristics and sperm DNA fragmentation in infertile men with low and high levels of seminal reactive oxygen species. Fertil Steril 2003, 94:2141-2146.

4. Pasqualotto FF, Sharma RK, Nelson DR, Thomas AJ Jr, Agarwal A: Relationship between oxidative stress, semen characteristics, and clinical diagnosis in men undergoing fertility investigation. Fertil Steril 2000, 73:459-464

5. Agarwal A, Makker K, Sharma R: Clinical relevance of oxidative stress in male factor infertility: an update. Am J Reprod Immunol 2008, 59:2-11.

6. Agarwal A, Sharma RK, Nallella KP, Thomas AJ Jr, Alvarez JG, Sikka SC: Reactive oxygen species as an independent marker of male factor infertility. Fertil Steril 2006, 86:878-885.

7. Sharma RK, Pasqualotto FF, Nelson DR, Thomas AJ Jr, Agarwal A: The reactive oxygen species-total antioxidant capacity score is a new measure of oxidative stress to predict male infertility. Hum Reprod 1999, 14:2801-2807.

8. Pasqualotto FF, Sharma RK, Potts JM, Nelson DR, Thomas AJ, Agarwal A: Seminal oxidative stress in patients with chronic prostatitis. Urology 2000, 55:881-885.

9. Agarwal A, Prabakaran S, Allamaneni SS: Relationship between oxidative stress, varicocele and infertility: a meta-analysis. Reprod Biomed Online 2006, 12:630-633.

10. Agarwal A, Sharma RK, Desai NR, Prabakaran S, Tavares A, Sabanegh E: Role of oxidative stress in pathogenesis of varicocele and infertility. Urology 2009, 73:461-469.

11. Pasqualotto FF, Sundaram A, Sharma RK, Borges E Jr, Pasqualotto EB, Agarwal A: Semen quality and oxidative stress scores in fertile and infertile patients with varicocele. Fertil Steril 2008, 89:602-607.

12. Hamada A, Sharma R, du Plessis S, Willard B, Yadav S, Sabanegh E, Agarwal A: Two dimensional differential in-gel electrophoresis-based proteomics of male gametes in relation to oxidative stress. Fertil Steril 2013, 99:1216-1226.

13. Vazquez L, Mónica H: Proteomic analysis and sperm physiopathology: the two-dimensional difference in gel electrophoresis approach. Fertil Steril 2013, 99:1199-1200.

14. de Mateo S, Estanyol JM, Oliva R: Methods for the analysis of the sperm proteome. Methods Mol Biol 2013, 927:411-422.

15. de Mateo S, Martínez-Heredia J, Estanyol JM, Domínguez-Fandos D, Vidal-Taboada JM, Ballescà JL, Oliva R: Marked correlations in protein expression identified by proteomic analysis of human spermatozoa. Proteomics 2007, 7:4264-4277.

16. Oliva R, De Mateo S, Castillo J, Azpiazu R, Oriola J, Ballescà JL: Methodological advances in sperm proteomics. Hum Fertil 2010, 13:263-267. 
17. Baker MA: The 'omics revolution and our understanding of sperm cell biology. Asian J Androl 2011, 13:6-10.

18. Govindaraju A, Dogan S, Rodriguez-Osorio N, Grant K, Kaya A, Memili E: Delivering value from sperm proteomics for fertility. Cell Tissue Res 2012, 349:783-793.

19. Baker MA, Nixon B, Naumovski N, Aitken RJ: Proteomic insights into the maturation and capacitation of mammalian spermatozoa. Syst Biol Reprod Med 2012, 58:211-217.

20. Parte PP, Rao P, Redij S, Lobo V, D'Souza SJ, Gajbhiye R, Kulkarni V: Sperm phosphoproteome profiling by ultra performance liquid chromatography followed by data independent analysis (LC-MS(E)) reveals altered proteomic signatures in asthenozoospermia. J Proteomics 2012, 75:5861-5871.

21. Baker MA, Naumovski N, Hetherington L, Weinberg A, Velkov T, Aitken RJ: Head and flagella subcompartmental proteomic analysis of human spermatozoa. Proteomics 2013, 13:61-74.

22. World Health Organization: WHO Laboratory Manual for the Examination and Processing of Human Semen. 5th ed. 5th edition. Cambridge: World Health Organization; 2010

23. Benjamin D, Sharma RK, Moazzam A, Agarwal A: Methods for the detection of ROS in human sperm samples. In Studies on Men's Health and Fertility. Edited by Agarwal A, Aitken RJ, Alvarez JG. New York, NY: Springer Science+Business Media; 2012:257-273.

24. Boyle E, Weng S, Gollub J, Jin H, Botstein D, Cherry JM, Sherlock G: GO: TermFinder-open source software for accessing Gene Ontology information and finding significantly enriched Gene Ontology terms associated with a list of genes. Bioinformatics 2004, 20:3710-3715.

25. GO term mapper. http://go.princeton.edu/cgi-bin/GOTermMapper.

26. The UniProt Consortium: Reorganizing the protein space at the Universal Protein Resource (UniProt). Nucleic Acids Res 2011, 40:D71-D75.

27. Bhatia VN, Perlman DH, Costello CE, McComb ME: Software tool for researching annotations of proteins: open-source protein annotation software with data visualization. Anal Chem 2009, 81:9819-9823.

28. Wu C, Orozco C, Boyer J, Leglise M, Goodale J, Batalov S, Hodge CL, Haase J, Janes J, Huss JW 3rd, Su Al: BioGPS: an extensible and customizable portal for querying and organizing gene annotation resources. Genome Biol 2009, 10:R130.

29. Ingenuity Pathway Analysis (IPA) from Ingenuity ${ }^{\circledR}$ Systems. Website Title: www.ingenuity.com.

30. Metacore ${ }^{\mathrm{TM}}$ from GeneGo Inc. Website: www.genego.com.

31. Martínez-Heredia J, de Mateo S, Vidal-Taboada JM, Ballescà JL, Oliva R: Identification of proteomic differences in asthenozoospermic sperm samples. Hum Reprod 2008, 23:783-791.

32. de Yebra L, Ballescá JL, Vanrell JA, Corzett M, Balhorn R, Oliva R: Detection of $\mathrm{P} 2$ precursors in the sperm cells of infertile patients who have reduced protamine P2 levels. Fertil Steril 1998, 69:755-759.

33. Zhao C, Huo R, Wang FQ, Lin M, Zhou ZM, Sha JH: Identification of several proteins involved in regulation of sperm motility by proteomic analysis. Fertil Steril 2007, 87:436-438.

34. Rajeev SK, Reddy KV: Sperm membrane protein profiles of fertile and infertile men: identification and characterization of fertility-associated sperm antigen. Hum Reprod 2004, 19:234-242.

35. Xu W, Hu H, Wang Z, Chen X, Yang F, Zhu Z, Fang P, Dai J, Wang L, Shi H, Li Z, Qiao Z: Proteomic characteristics of spermatozoa in normozoospermic patients with infertility. J Proteomics 2012, 75:5426-5436.

36. Nakamura N, Mori C, Eddy EM: Molecular complex of three testis-specific isozymes associated with the mouse sperm fibrous sheath: hexokinase 1, phosphofructokinase $M$, and glutathione S-transferase mu class 5 . Biol Reprod 2010, 82:504-515.

37. Nascimento JM, Shi LZ, Tam J, Chandsawangbhuwana C, Durrant B, Botvinick EL, Berns MW: Comparison of glycolysis and oxidative phosphorylation as energy sources for mammalian sperm motility, using the combination of fluorescence imaging, laser tweezers, and real-time automated tracking and trapping. J Cell Physiol 2008, 217:745-751.

38. Storey BT: Mammalian sperm metabolism: oxygen and sugar, friend and foe. Int J Dev Biol 2008, 52:427-437.

39. Terrell KA, Wildt DE, Anthony NM, Bavister BD, Leibo SP, Penfold LM, Marker $\mathrm{LL}$, Crosier AE: Oxidative phosphorylation is essential for felid sperm function, but is substantially lower in cheetah (Acinonyx jubatus) compared to domestic cat (Felis catus) ejaculate. Biol Reprod 2011, 85:473-481.
40. Elkina YL, Atroshchenko MM, Bragina EE, Muronetz VI, Schmalhausen EV: Oxidation of glyceraldehyde-3-phosphate dehydrogenase decreases sperm motility. Biochemistry 2011, 76:268-272

41. Sharma R, Agarwal A: Spermatogenesis: An overview. In Human sperm chromatin: Structure and Function. Sperm Chromatin. Biological and Clinical Applications in Male Infertility and Assisted Reproduction. Edited by Zini A, Agarwal A. New York: Springer Science + Business Media; 2012:19-44.

42. Lilja H, Abrahamsson PA, Lundwall A: Semenogelin, the predominant protein in human semen. Primary structure and identification of closely related proteins in the male accessory sex glands and on the spermatozoa. J Biol Chem 1989, 264:1894-1900.

43. Lilja H, Lundwall A: Molecular cloning of epididymal and seminal vesicular transcripts encoding a semenogelin-related protein. Proc Natl Acad Sci USA 1992, 89:4559-4563.

44. de Lamirande E, Yoshida K, Yoshiike TM, Iwamoto T, Gagnon C: Semenogelin, the main protein of semen coagulum, inhibits human sperm capacitation by interfering with the superoxide anion generated during this process. J Androl 2001, 22:672-679.

45. Auger J, Eustache F, Maceiras P, Broussard C, Chafey P, Lesaffre C, Vaiman D, Camoin L, Auer J: Modified expression of several sperm proteins after chronic exposure to the antiandrogenic compound vinclozolin. Toxicol Sci 2010, 117:475-484

46. Feder ME, Hofmann GE: Heat-shock proteins, molecular chaperones, and the stress response: evolutionary and ecological physiology. Annu Rev Physiol 1999, 61:243-282

47. Katschinski DM: On heat and cells and proteins. News Physio/ Sci 2004, 19:11-15.

48. Sung DY, Guy CL: Physiological and molecular assessment of altered expression of Hsc70-1 in Arabidopsis. Evidence for pleiotropic consequences. Plant Physiol 2003, 132:979-987.

49. Folk JE: Transglutaminases. Annu Rev Biochem 1980, 49:517-531.

50. Lorand L, Conrad SM: Transglutaminases. Mol Cell Biochem 1984, 58:9-35.

51. Shin DM, Jeon JH, Kim CW, Cho SY, Lee HJ, Jang GY, Jeong EM, Lee DS, Kang JH, Melino G, Park SC, Kim IG: TGF beta mediates activation of transglutaminase 2 in response to oxidative stress that leads to protein aggregation. FASEB J 2008, 22:2498-2507.

52. Li Y, Okumura K, Nomura S, Maeda N, Miyasho T, Yokota H: Oxidatively damaged proteins in the early stage of testicular toxicities in male rats by orally administered with a synthetic oestrogen, diethylstilbestrol. Reprod Toxicol 2011, 31:26-34.

53. Immenschuh S, Baumgart-Vogt E, Tan M, Iwahara S, Ramadori G, Fahimi HD: Differential cellular and subcellular localization of heme-binding protein 23/peroxiredoxin I and heme oxygenase-1 in rat liver. J Histochem Cytochem 2003, 51:1621-1631.

54. Wood ZA, Poole LB, Karplus PA: Peroxiredoxin evolution and the regulation of hydrogen peroxide signaling. Science 2003, 300:650-653.

55. O'Flaherty C, de Souza AR: Hydrogen peroxide modifies human sperm peroxiredoxins in a dose-dependent manner. Biol Reprod 2011, 84:238-247.

56. Gong S, Gabriel MC, Zini A, Chan P, O'Flaherty C: Low amounts and high thiol oxidation of peroxiredoxins in spermatozoa from infertile men. J Androl 2012, 33:1342-1351.

57. Rey RA, Musse M, Venara M, Chemes HE: Ontogeny of the androgen receptor expression in the fetal and postnatal testis: its relevance on Sertoli cell maturation and the onset of adult spermatogenesis. Microsc Res Tech 2009, 72:787-795.

58. Stanton PG, Sluka P, Foo CF, Stephens AN, Smith Al, McLachlan Rl, O'Donnell L: Proteomic changes in rat spermatogenesis in response to in vivo androgen manipulation; impact on meiotic cells. PLoS One 2012, 7:e41718.

59. Wang RS, Yeh S, Tzeng CR, Chang C: Androgen receptor roles in spermatogenesis and fertility: lessons from testicular cell-specific androgen receptor knockout mice. Endocr Rev 2009, 30:119-132.

60. Singh J, O'Neill C, Handelsman DJ: Induction of spermatogenesis by androgens in gonadotropin-deficient (hpg) mice. Endocrinology 1995, 136:5311-5321.

61. Tamai KT, Monaco L, Nantel F, Zazopoulos E, Sassone-Corsi P: Coupling signalling pathways to transcriptional control: nuclear factors responsive to cAMP. Recent Prog Horm Res 1997, 52:121-139. discussion 139-40.

62. Hogeveen KN, Sassone-Corsi P: Regulation of gene expression in post-meiotic male germ cells: CREM-signalling pathways and male fertility. Hum Fertil 2006, 9:73-79. 
63. Monaco L, Kotaja N, Fienga G, Hogeveen K, Kolthur US, Kimmins S, Brancorsin S, Macho B, Sassone-Corsi P: Specialized rules of gene transcription in male germ cells: the CREM paradigm. Int J Androl 2004, 27:322-327.

64. Weinbauer GF, Behr R, Bergmann M, Nieschlag E: Testicular cAMP responsive element modulator (CREM) protein is expressed in round spermatids but is absent or reduced in men with round spermatid maturation arrest. Mol Hum Reprod 1998, 4:9-15.

doi:10.1186/1477-7827-11-48

Cite this article as: Sharma et al:: Proteomic analysis of human

spermatozoa proteins with oxidative stress. Reproductive Biology and Endocrinology 2013 11:48

\section{Submit your next manuscript to BioMed Central and take full advantage of:}

- Convenient online submission

- Thorough peer review

- No space constraints or color figure charges

- Immediate publication on acceptance

- Inclusion in PubMed, CAS, Scopus and Google Scholar

- Research which is freely available for redistribution 